\title{
Consumo de matéria seca e desempenho de novilhas das raças Girolando e Guzerá sob suplementação na caatinga, na época chuvosa, em Pernambuco, Brasil $^{1}$
}

\author{
Daniel Fernando Ydoyaga Santana ${ }^{2}$, Mario de Andrade Lira ${ }^{3,5}$, Mércia Virginia Ferreira dos \\ Santos $^{4,5}$, Marcelo de Andrade Ferreira ${ }^{4,5}$, Djalma Cordeiro dos Santos ${ }^{3}$, Alexandre Carneiro \\ Leão de Mello ${ }^{4}$, José Carlos Batista Dubeux Júnior ${ }^{4,5}$, Gherman Garcia Leal de Araujo ${ }^{6,5}$ \\ 1 Trabalho parcialmente financiado pela EMBRAPA \\ 2 Pós-graduando do PDIZ-UFRPE/UFPB/UFC. \\ 3 Instituto Agronomico de Pernambuco. \\ ${ }^{4}$ Universidade Federal Rural de Pernambuco. \\ ${ }^{5}$ Bolsista CNPq. \\ ${ }^{6}$ Embrapa Semiárido.
}

RESUMO - Com os objetivos de estimar o consumo de matéria seca e avaliar a variação do peso vivo de novilhas, conduziu-se um experimento no período entre março e julho de 2003, com quatro estratégias de suplementação: sem suplementação (controle); torta de algodão (1 kg); palma-forrageira (10 kg); e de palma $(5,0 \mathrm{~kg})+$ torta de algodão $(0,5 \mathrm{~kg})$. O fornecimento de suplemento não influenciou o consumo de matéria seca (MS) do pasto nativo, no entanto afetou o consumo de MS total. O consumo de matéria seca total diferiu entre as raças, com valores de 5,44 e 6,75 kg/dia, respectivamente, para as raças Guzerá e Girolando. Nos animais sob suplementação com torta de algodão, o consumo de MS total foi superior ao do grupo controle (sem suplementação), porém semelhante ao daqueles sob suplementação com palma-forrageira e com torta de algodão + palma-forrageira. O ganho de peso vivo médio diário (de 517 e 434 g/animal, respectivamente, para os grupos Girolando e Guzerá) não diferiu entre as raças nem foi influenciado pela interação raça × suplementação. Entre as estratégias de suplementação, no entanto, os valores tiveram diferença significativa e foram de 412, 620, 371 e 498 g/animal/dia, respectivamente, para os grupos controle e sob suplementação com torta de algodão; palma-forrageira; torta de algodão + palma-forrageira. No semiárido de Pernambuco, a suplementação com 1 kg de torta de algodão na época chuvosa do ano melhora o ganho de peso médio diário, independentemente da raça do animal.

Palavras-chave: Opuntia ficus indica Mill, óxido crômico, suplementação, torta de algodão

\section{Dry matter intake and performance of Girolando and Guzerá heifers and Guzerá under supplementation in caatinga, during the rainy season, in Pernambuco, Brazil}

ABSTRACT - To estimate dry matter intake and to evaluate variation on live weight of heifers, an experiment was conducted from March to July 2003, with the following supplementation strategies: no supplementation (control), cottonseed cake $(1 \mathrm{~kg})$; spineless cactus $(10 \mathrm{~kg})$; spineless cactus $+0.5 \mathrm{~kg}$ of cottonseed cake $(5 \mathrm{~kg})$. Dry matter intake of native pasture was not affected by supplementation, but it affected total dry matter intake. Intake of total dry matter (DM) differed among breeds with values of 5.44 and $6.75 \mathrm{~kg} /$ day, respectively for Guzerat and Girolando breeds. For animal fed cottonseed cake supplementation, total DM intake was higher than in the control group (no supplementation), however, it was similar for those under spineless cactus and cottonseed cake + spinelles cactus supplementation. Daily average body weight gain (517 and 434 g/animal, respectively, for Girolando and Guzerat groups) did not differ among breeds neither was affected by breed $\times$ supplementation interaction. However, among strategies of suplementation, values were significantly different and they were 412, 620, 371 and 498 g/animal/day, respectively, for control and cottonseed cake suplementation group; spineless cactus; cottonseed cake + spineless cactus. In Pernambuco semiarid, $1 \mathrm{~kg}$ of cottonseed cake supplementation improved daily average weight gain, regardless to breed of the animal during the rainy season.

Key Words: cottonseed cake, cromic oxid, Opuntia ficus indica Mill, suplementation 


\section{Introdução}

Grande parte dos rebanhos do semiárido brasileiro é criada extensivamente na caatinga, com índices de produção geralmente muito baixos, como resultado das flutuações na composiçao botânica, da disponibilidade e do valor nutricional das forragens, do manejo inadequado, entre outros (Lira et al., 2006; Moreira et al., 2007; Marques et al., 2008).

A maior parte das pesquisas desenvolvidas visando aumentar a eficiência dos sistemas de produção animal na caatinga é desenvolvida no período seco do ano. Entretanto, a maior disponibilidade de forragem na época chuvosa deve ser racionalizada para alimentação animal, como forma de potencializar o desempenho animal no período mais favorável. Por outro lado, conforme Lopes et al. (1998), as variações no valor nutritivo dos pastos também ocorrem na época das chuvas e são capazes de influenciar a produção animal.

De acordo com Figueiredo et al. (2008), objetivando melhorar o potencial forrageiro e genético do animal, desenvolveu-se a tecnologia de uso de suplementos concentrados no período das águas. Segundo Thiago \& Costa (2004), o objetivo é fornecer nutrientes em quantidades adequadas para suprir as demandas minerais, proteicas e/ou energéticas dos animais e compensar a deficiência do pasto, tendo como princípio básico evitar o efeito substitutivo do pasto pelo suplemento.

A maior parte da produção bovina ocorre em pastagens de médio a baixo valor nutricional e faz com que o consumo de matéria seca seja um dos principais determinantes do processo produtivo (Lima et al., 2008). O consumo voluntário, principalmente em condições de pastejo, é influenciado pela combinação de muitos fatores inerentes ao animal, à planta, ao ambiente e ao manejo utilizado.

Experimentos estimando o consumo de MS de bovinos em crescimento na caatinga não foram encontrados na literatura. Bovinos das raças Guzerá e Girolando criados na caatinga apresentam baixos índices zootécnicos, sobretudo elevada idade ao primeiro parto. Esse fato pode ser atribuído ao manejo alimentar inadequado ao longo das fases de cria e recria dos animais.

Assim, os objetivos neste trabalho foram estimar o consumo de matéria seca e avaliar a variação do peso vivo de novilhas em uma caatinga manipulada sob suplementação na época chuvosa do ano.

\section{Material e Métodos}

O trabalho foi conduzido no período de março a julho de 2003 na Estação Experimental pertencente ao Instituto Agronômico de Pernambuco (IPA), localizada no município de Serra Talhada - PE. A precipitação pluvial no período de janeiro a junho de 2003 foi de 605,1 mm (Figura 1) e a temperatura média anual de $25,7^{\circ} \mathrm{C}$. A cobertura florística da região é do tipo caatinga, bastante complexa e irregular, com predominância de espécies arboreo-arbustivas. A topografia da área experimental é variável, com parte plana até algumas áreas mais acidentadas e predominância de solo do tipo Bruno não-cálcico, típico e representativo da região, com manchas de Podzólico Vermelho-Amarelo medianamente profundo, e Regossolo (EMBRAPA, 1999).

A área experimental constou de aproximadamente 96 hectares de caatinga. Parte da área foi modificada pela introdução, nos anos 80, dos capins buffel (Cenchrus ciliaris L.) e corrente (Urochloa mosambicensis (Hack) Dandy).

Para as avaliações do consumo e desempenho animal, foram utilizadas 24 novilhas (12 da raça Guzerá e 12 da raça Girolando - 5/8 Holandês 3/8 Zebu) com peso inicial de 187 e 198 kg e idade média inicial de 18 e 20 meses, respectivamente. A taxa de lotação utilizada foi de 6 hectares por unidade animal, considerando também dois animais fistulados no esôfago utilizados para estudo da dieta animal (Tabela 1).

As estratégias de alimentação foram: sem suplementação; torta de algodão (1,0 kg/animail/dia); palma-forrageira (10,0 kg/animal/dia); e torta de algodão $(0,5 \mathrm{~kg})+$ palmaforrageira (5,0 kg/animal/dia).

Utilizou-se o delineamento experimental em blocos ao acaso, com arranjo fatorial $2 \times 4$, composto de duas raças e quatro tipos de suplemento, cada um avaliado com três repetições (novilhas). Em baias individuais, os animais recebiam suplementação às $10 \mathrm{~h} 30 \mathrm{~min}$, conforme as estratégias predeterminadas. Em torno das 13h30min, os animais retornavam à caatinga, onde permaneciam até o

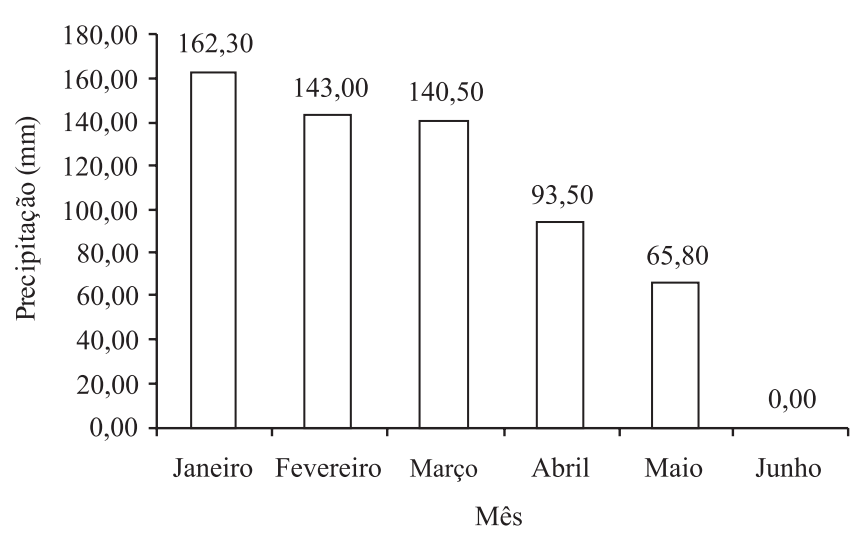

Figura 1 - Precipitações pluviométricas do primeiro semestre do ano, 2003. 
horário da suplementação do dia seguinte. Diariamente, sobras dos suplementos eram pesadas e descartadas, exceto nos dias de coleta de amostra para análise bromatológica.

A quantidade de suplementos oferecida foi calculada de maneira a propiciar um ganho de peso vivo de $0,2 \mathrm{~kg} /$ animal/dia, supondo que a caatinga na época das águas fornece nutrientes suficientes para garantir o desempenho dos animais na taxa lotação estipulada (Silva et al., 2001). O manejo sanitário foi o mesmo empregado na estação experimental, com fornecimento de sal mineral e água à vontade.

As pesagens dos animais foram realizadas no início do experimento e a cada 28 dias, por volta das $7 \mathrm{~h}$, com os animais em jejum prévio de água e alimento de aproximadamente 16 horas.

A variação do peso vivo médio diário por animal foi calculada pela seguinte fórmula: GPVMD $=(\mathrm{PF}-\mathrm{PI}) \times 1000$ / DE, em que: GPVMD = ganho de peso vivo médio diário (g/dia); PF = peso final (kg); PI = peso inicial (kg); DE = dias do experimento.

O consumo voluntário foi determinado pela relação entre a quantidade de matéria seca fecal excretada, estimada utilizando-se um indicador externo, óxido crômico $\left(\mathrm{Cr}_{2} \mathrm{O}_{3}\right)$, e a MS indigestível, um indicador interno, fibra em detergente ácido indigestível (Ruas et al., 2000). A fase de adaptação ao indicador externo foi de sete dias e as coletas foram realizadas no oitavo e nono dias. Às $9 \mathrm{~h}$ eram fornecidos aos animais 10 g de óxido crômico/animal, acondicionados em cartuchos de papel e introduzidos via oral, em dose única. As amostras fecais eram coletadas por animal, diretamente no reto, pela manhã, em quantidades de aproximadamente 300 g. Os materiais coletados foram acondicionados em pratos de alumínio, identificados e colocados em estufa com circulação forçada de ar, a $55^{\circ} \mathrm{C}$, por 72 horas. Para a realização das análises, as amostras foram processadas em moinho tipo Willey com peneira de $1 \mathrm{~mm}$.

Os teores de cromo ( $\mathrm{Cr}$ ) foram analisados por espectrofotometria de absorção atômica, conforme metodologia descrita por Williams et al. (1962). Para determinação da produção fecal, foi utilizada a fórmula proposta por Burns et al. (1994): $\mathrm{PMSF}=\mathrm{OF} / \% \mathrm{OF}$, em que: $\mathrm{PMSF}=$ produção de $\mathrm{MS}$ fecal (g/dia); $\mathrm{OF}=\mathrm{Cr}_{2} \mathrm{O}_{3}$ fornecido (g/dia); \%OF = concentração de óxido de cromo nas fezes (g/g MS).

A fibra em detergente ácido indigestível (FDAi) foi determinada conforme descrito por Itavo et al. (2002), com base na digestibilidade in situ, por um período de 144 horas.

A estimativa do consumo de matéria seca foi calculada pela seguinte equação: CMS $=\{[($ MSFE $\times$ \%FAiF $)-$ FDAiS] / \%FDAiForr \} + CMSS, em que: CMS = consumo de MS (kg/dia); MSFE = MS fecal excretada (kg/dia); $\mathrm{FDAiF}=$ concentração do indicador nas fezes $(\mathrm{kg} / \mathrm{kg})$; FDAiS = indicador presente no suplemento $(\mathrm{kg} / \mathrm{dia})$; FDAiForr = concentração do indicador na forragem $(\mathrm{kg} / \mathrm{kg}) ;$ e CMSS = consumo de matéria seca do suplemento (kg/dia).

Os teores de carboidratos totais foram obtidos pela equação: CT = 100-(\%PB+\%EE+\%Cinzas)(Sniffenetal.,1992), enquanto os carboidratos não-fibrosos (CNF), pela diferença entre carboidratos totais e fibra em detergente neutro. Os teores de nutrientes digestíveis totais (NDT) foram obtidos conforme descrito por Sniffen et al. (1992). Para os ingredientes torta de algodão e palma-forrageira, foram considerados os valores de NDT apresentados por Valadares Filho et al. (2002).

Os suplementos fornecidos e as sobras foram pesados diariamente e, posteriormente, as sobras descartadas. No final de cada período experimental, foram coletadas amostras das sobras, dos suplementos fornecidos e do pasto, que foram pesadas, identificadas e colocadas em estufa com circulação forçada de ar, a $55^{\circ} \mathrm{C}$, por 48 horas, para posteriores análises de MS, proteína bruta (PB), matéria mineral (MM) e extrato etéreo (EE), segundo Silva \& Queiroz (2002), e fibra em detergente neutro (FDN) e em detergente ácido (FDA), conforme descrito por Van Soest et al. (1991).

Os dados foram analisados pelo programa estatístico Swntia (EMBRAPA, 1996), por meio de análise de variância, e as diferenças entre as médias comparadas pelo teste Duncan, a 5\% de significância.

Tabela 1 - Composição nutricional e digestibilidade in situ da forragem e dos suplementos fornecidos

\begin{tabular}{lcccc}
\hline Item (\% MS) & Torta de algodão & Palma-forrageira & Torta + palma-forrageira & Pasto (caatinga) \\
\hline Matéria seca & 88,1 & 9,0 & 48,5 & 55,7 \\
Proteína bruta & 34,5 & 6,9 & 20,7 & 65,0 \\
Nutrientes digestíveis totais & - & - & 42,9 & 5,6 \\
Fibra em detergente neutro & 58,9 & 26,9 & 33,5 & 5,0 \\
Fibra em detergente ácido & 44,8 & 22,3 & 2,3 & 4,0 \\
Extrato etéreo & 2,6 & 2,1 & 11,2 & 8,0 \\
Matéria mineral & 8,2 & 14,5 & 70,2 & 8,8 \\
Digestibilidade in situ da MS (\%) & 66,8 & 73,6 & & 31,8 \\
\hline
\end{tabular}




\section{Resultados e Discussão}

Os consumos de matéria seca dos suplementos, do pasto e de matéria seca total apresentaram diferenças significativas $(\mathrm{P}<0,05)$ entre as raças avaliadas (Tabela 2$)$, com interações não-significativas. As novilhas das raças Guzerá e Girolando apresentaram consumo total de 5,44 e $6,75 \mathrm{~kg} / \mathrm{MS} /$ dia, respectivamente. O maior consumo de MS (kg/dia) pelos animais da raça Girolando possivelmente deveu-se ao maior peso vivo (PV) desses animais em relação aos Guzerá, uma vez que a diferença entre as médias para o consumo de MS (\% PV) não foi significativa.

O consumo de matéria seca do pasto não foi influenciado $(\mathrm{P}>0,05)$ pelo fornecimento dos suplementos, ao contrário do consumo de matéria seca total, que foi influenciado $(\mathrm{P}<0,05)$ pelo consumo de suplementos. Nos animais sob suplementação com torta de algodão, o consumo de matéria seca total foi superior $(\mathrm{P}<0,05)$ ao observado no grupo controle e semelhante $(\mathrm{P}>0,05)$ ao dos animais sob suplementação com palma-forrageira ou com torta de algodão + palma-forrageira. Observou-se efeito aditivo da suplementação, uma vez que, além do aumento do ganho de peso (Tabela 5), não houve diferença significativa $(\mathrm{P}>0,05)$ no consumo de pasto (Tabela 2). Horn \& McCollun (1987) mencionaram que a suplementação a animais em pastejo em níveis de até $0,5 \%$ do PV não reduz o consumo de forragem. O consumo dos suplementos foi até $0,3 \%$ do PV e, segundo Herd (1997), nesse nível de suplementação, o consumo do suplemento promove efeito aditivo ao consumo do pasto sem ocorrência de substituição. Em geral, o princípio básico na suplementação a pasto é evitar ou reduzir o efeito substitutivo, objetivando promover o efeito aditivo, aumentando a ingestão e a digestibilidade das forragens (Paulino, 2001).

O maior consumo de MS dos animais sob suplementação com torta de algodão pode estar associado a um conjunto de características da pastagem que influenciam negativamente a disponibilidade de proteína para o animal, como: alta porcentagem de proteína insolúvel em detergente ácido (PIDA), baixa digestibilidade in situ da MS, alto teor de fibra (Santos et al., 2009) e, provavelmente, altos teores de lignina (Moreira et al., 2006) e taninos (Araújo Filho et al., 2002).

A vegetação da caatinga inclui forrageiras com teores de proteína bruta na MS superiores a $200 \mathrm{~g} / \mathrm{kg}$, porém a digestibilidade normalmente é baixa (Moreira et al., 2006; Santos et al., 2009), fato que pode estar associado aos altos teores de taninos de algumas espécies da caatinga, notadamente as arbustivas e arbóreas, o que, segundo Rooney (2005), pode promover redução de 5 a $10 \%$ na eficiência alimentar, dependendo da espécie animal. Araújo Filho et al. (2002), estudando a fenologia e o valor nutritivo de espécies arboreo-arbustivas na caatinga, concluíram que o teor de taninos totais pode não ser um fator prejudicial ao consumo de espécies da caatinga, mas as altas concentrações de lignina reduzem a digestibilidade. Estudos realizados por Moreira et al. (2006) no período chuvoso na caatinga evidenciaram teores de 49,53\% de PIDA na extrusa de bovinos, além de teores de lignina variando de 14,63 a 16,35\%, respectivamente, características associadas à baixa digestibilidade da forragem.

O consumo de matéria seca total observado (2,55\% PV) foi inferior ao observado or Ferreira (2005), de 2,98\%, em animais de 15 meses de idade sob suplementação com ração com 50\% de palma forrageira. Segundo Romney \& Gill (2000), o consumo em relação ao PV em animais jovens tende a ser maior, em decorrência da maior exigência nutricional.

De acordo com o NRC (2001), as exigências de proteína metabolizável para mantença e ganho de peso médio de 475 g para novilhas em crescimento com peso vivo médio de 226 kg são de 98,3 e 202,1 g, respectivamente, que correspondem, para esse nível de desempenho, a 446 g PB/dia.

Tabela 2 - Consumo de pasto e de suplementos em novilhas sob suplementação na estação chuvosa no semiárido de Pernambuco

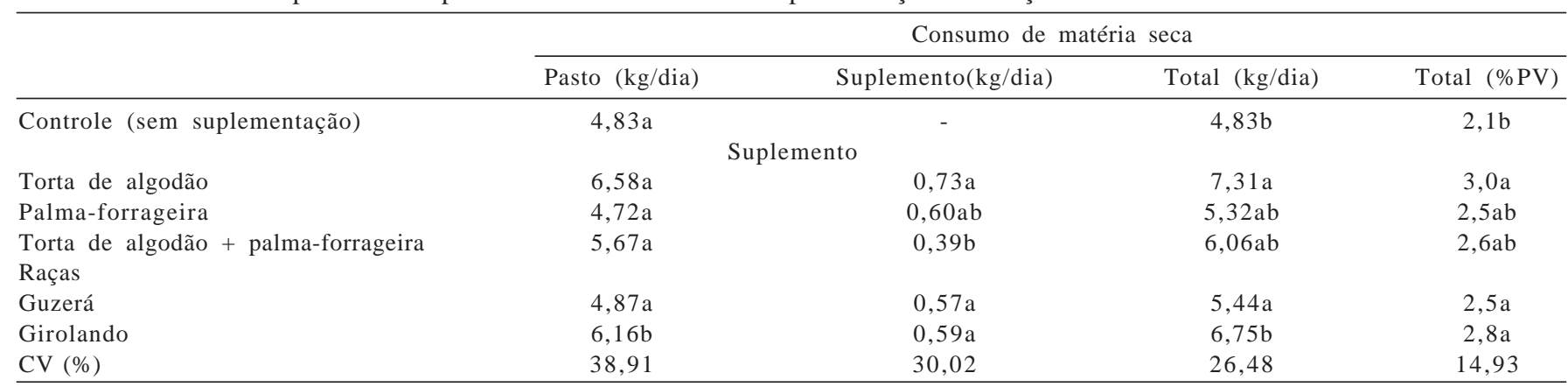

Médias seguidas por igual letra, no sentido da coluna, para cada parâmetro avaliado, não diferem entre si $(\mathrm{P}>0,05)$ pelo teste de Duncan. 
Já as exigências de NDT para mantença e ganho sugeridas por esse conselho são de 643 e 2540 g, respectivamente.

As exigências de mantença da categoria animal utilizada foram atingidas. O maior $(\mathrm{P}<0,05)$ consumo total de proteína e de proteína e energia influenciaram significativamente o ganho de peso. Este resultado pode estar relacionado à provável deficiência proteica do pasto, embora o teor de PB no grupo controle estimado pela análise da extrusa tenha sido de $15,2 \%$, superior ao de 13,2\% (Ydoyaga Santana, 2006), o que indicando que este nutriente não foi limitante na dieta. O resultado decorre, provavelmente, da baixa digestibilidade de PB no pasto, de 34,8\%, em média, sempre inferior a 38,53\%, além dos elevados teores de proteína insolúvel em detergente ácido (PIDA) da extrusa, em média de 40,62\% (Ydoyaga Santana, 2006).

Mesmo havendo diferença $(\mathrm{P}<0,05)$ no consumo total de NDT com a suplementação energética (Tabela 3), não foi observada diferença $(\mathrm{P}<0,05)$ no ganho de peso dos animais em comparação ao grupo controle, provavelmente em decorrência da relação proteína:energia, uma vez que parte da proteína dessa dieta é oriunda do pasto, que apresentou baixa digestibilidade. Além disso, o consumo total de proteína do grupo que recebeu palma-forrageira não diferiu $(\mathrm{P}<0,05)$ do obtido nos grupos controle e com suplementação com torta de algodão + palma-forrageira e foi inferior $(\mathrm{P}>0,05)$ ao das novilhas que receberam torta de algodão.
A diferença $(\mathrm{P}<0,05)$ no consumo total de proteína e NDT não influenciou $(\mathrm{P}>0,05)$ o ganho do $\mathrm{PV}$ entre as raças. O peso vivo final das novilhas (Tabela 4) e o ganho de peso vivo médio diário não apresentaram diferenças $(\mathrm{P}>0,05)$ entre raças, nem foi afetado pela interação raça $\times$ suplementação. Os valores foram de 517 e 434 g/animal para as raças Girolando e Guzerá, respectivamente, com média de 475 g/animal/dia entre ambas. O consumo de suplementos, no entanto, ocasionou diferença significativa $(\mathrm{P}<0,05)$ no ganho médio diário (Tabela 5), que foi maior $(\mathrm{P}>0,05)$ no grupo sob suplementação com torta de algodão + palma-forrageira, seguido daquele que recebeu torta de algodão $(P<0,05)$. Os animais sem suplementação e sob suplementação com palma-forrageira e com torta de algodão + palma-forrageira não apresentaram diferenças significativas entre si.

A maior resposta à suplementação com torta de algodão pode ser atribuída ao maior consumo de matéria seca total pelos animais (Tabela 3), o que elevou o aporte de nutrientes. Estudos têm comprovado que é alta a correlação entre consumo de forragem e o ganho de peso (Paulino, 2001; Barros et al., 2004). A semelhança entre o desempenho médio dos animais sem suplementação e o daqueles sob suplementação deveu-se, provavelmente, à taxa de lotação (6 ha/UA), que permitiu aos animais seleção da forragem. Além disso, a presença expressiva de capim-buffel

Tabela 3 - Consumo de proteína e nutrientes digestíveis totais em novilhas sob suplementação na estação chuvosa no semiárido de Pernambuco

\begin{tabular}{|c|c|c|c|c|c|c|}
\hline & \multicolumn{6}{|c|}{ Consumo } \\
\hline & \multicolumn{3}{|c|}{ Proteína } & \multicolumn{3}{|c|}{ NDT } \\
\hline & Pasto & Suplemento & Total & Pasto & Suplemento & Total \\
\hline $\begin{array}{l}\text { Controle (sem suplementação) } \\
\text { Suplemento }\end{array}$ & $608,58 b$ & 0 & $608,58 c$ & $2704,80 \mathrm{~b}$ & 0 & $2704,80 \mathrm{c}$ \\
\hline Torta de algodão & $829,08 a$ & $251,85 a$ & $1080,93 a$ & $3684,80 \mathrm{a}$ & $482,31 \mathrm{a}$ & $4167,11 \mathrm{a}$ \\
\hline Palma-forrageira & $594,72 \mathrm{c}$ & $41,40 \mathrm{c}$ & $636,12 b c$ & 2643,20b & $384,80 \mathrm{ab}$ & $3027,20 b$ \\
\hline $\begin{array}{l}\text { Torta de algodão + palma-forrageira } \\
\text { Raças }\end{array}$ & $714,42 \mathrm{ab}$ & $80,73 b$ & $795,15 b$ & $3175,20 a b$ & $253,50 b$ & $3428,70 a b$ \\
\hline Guzerá & $613,62 a$ & $135,43 a$ & $749,05 a$ & $2727,20 \mathrm{a}$ & $370,50 a$ & $3097,70 a$ \\
\hline Girolando & $776,16 \mathrm{~b}$ & $140,18 a$ & $916,34 b$ & $3449,60 b$ & $383,50 a$ & $3833,10 \mathrm{~b}$ \\
\hline CV (\%) & 27,09 & 13,88 & 15,18 & 29,92 & 16,65 & 14,79 \\
\hline
\end{tabular}

Médias seguidas por letra igual na coluna, para cada parâmetro avaliado, não diferem entre si $(\mathrm{P}>0,05)$ pelo teste de Duncan.

Tabela 4 - Peso vivo médio inicial e final em novilhas sob suplementação na estação chuvosa no semiárido de Pernambuco

\begin{tabular}{|c|c|c|c|c|c|}
\hline \multirow[b]{2}{*}{ Peso vivo (kg) } & \multirow[b]{2}{*}{$\begin{array}{c}\text { Controle } \\
\text { (sem suplemento) }\end{array}$} & \multicolumn{3}{|c|}{ Suplemento } & \multirow[b]{2}{*}{ Média } \\
\hline & & $\begin{array}{l}\text { Torta de } \\
\text { algodão }\end{array}$ & Palma-forrageira & $\begin{array}{c}\text { Torta de algodão + } \\
\text { palma-forrageira }\end{array}$ & \\
\hline Guzerá (inicial) & 193 & 188 & 181 & 185 & 187 \\
\hline Guzerá (final) & 248 & 260 & 230 & 251 & 248 \\
\hline Girolando (inicial) & 193 & 210 & 190 & 201 & 198 \\
\hline Girolando (final) & 253 & 312 & 244 & 274 & 271 \\
\hline
\end{tabular}


Tabela 5 - Ganho de peso vivo médio diário em novilhas sob suplementação na estação chuvosa no semiárido de Pernambuco

\begin{tabular}{|c|c|c|c|c|c|c|}
\hline & \multirow[b]{2}{*}{$\begin{array}{c}\text { Controle } \\
\text { (sem suplemento) }\end{array}$} & \multicolumn{3}{|c|}{ Suplemento } & \multirow[b]{2}{*}{ Média } & \multirow[b]{2}{*}{ CV $(\%)$} \\
\hline & & $\begin{array}{l}\text { Torta de } \\
\text { algodão }\end{array}$ & Palma-forrageira & $\begin{array}{c}\text { Torta de algodão + } \\
\text { palma-forrageira }\end{array}$ & & \\
\hline \multicolumn{7}{|c|}{ Ganho de peso médio (g/dia) } \\
\hline Guzerá & 393 & 514 & 353 & 472 & $434 \mathrm{a}$ & 48,9 \\
\hline Girolando & 431 & 726 & 388 & 521 & $517 a$ & 42,9 \\
\hline Média & $412 b$ & $620 a$ & $371 b$ & $498 \mathrm{ab}$ & 475 & \\
\hline
\end{tabular}

Médias seguidas de letra igual na coluna, para cada parâmetro avaliado, não diferem entre si ( $P>0,05)$ pelo teste Duncan.

(Cenchrus ciliaris L.) e capim-corrente (Urochloa mosambicensis (Hack) Dandy) nos piquetes (Ydoyaga Santana et al., 2005) favoreceu a elevação da massa de forragem disponível. Moura (1987) e Silva et al. (2001), em pesquisa com novilhas $3 / 4$ Zebu em pastagem de caatinga nativa e, considerando a época chuvosa do ano na mesma região deste estudo, constataram ganho médio de peso vivo de 348 e 365 g/dia, respectivamente, inferiores aos obtidos nesse experimento.

Segundo Paulino et al. (2002), frequentemente os animais respondem à suplementação proteica na estação das águas, período em que a qualidade da forragem, em termos de digestibilidade e conteúdo de proteína, é alta, possibilitando ganhos adicionais de 200 a 300 g. Esse comportamento foi observado por meio das médias de ganho de peso vivo com as suplementações com torta de algodão e torta de algodão + palma-forrageira, em relação ao grupo controle, cujos valores foram de 208 e 86 g a mais, respectivamente, em relação aos animais que não receberam suplemento (Tabela 5).

Apesar do efeito aditivo da suplementação com torta de algodão (1 kg/animal/dia), relacionando os custos desse suplemento (de R \$ 0,7/kg e de R \$2,00/kg PV animal) aos ganhos médios obtidos com a suplementação, nas condições do experimento, não se justifica o uso desse concentrado na época chuvosa. Por outro lado, com vistas à reprodução, o ganho de 200 g/animal/dia com a suplementação proteica no período chuvoso provavelmente reduz a idade de entrada em serviço de novilhas de reposição. Assim, a suplementação proteica é uma estratégia a ser considerada visando elevar os índices reprodutivos do rebanho.

\section{Conclusões}

Na época chuvosa, a caatinga, quando manejada com lotação bem ajustada à quantidade de forragem disponível, possibilita consumo de matéria seca capaz de atender às exigências de mantença e proporcionar ganho de peso em novilhas Guzerá e Girolando. A suplementação com torta de algodão (1 kg), palma-forrageira (10 kg) ou com palmaforrageira $(5,0 \mathrm{~kg})+$ torta de algodão $(0,5 \mathrm{~kg})$ na época chuvosa não afeta o consumo de pasto nativo (caatinga) e propicia maiores ganhos diários em novilhas no semiárido, independentemente da raça. O consumo de matéria seca total das dietas é semelhante entre as raças Guzerá e Girolando.

\section{Referências}

ARAÚJO FILHO, J.A; CARVALHO, F.C.; SILVA, N.L. Fenología y valor nutritivo de follajes de algunas especies forrajeras de la caatinga. Agroforesteria en las Americas, v.9, n.1-4, p.33-34, 2002.

BARROS, N.N.; ROSSETTI, A.G.; CARVALHO, R.B. Feno de cunhã (Clitoria ternatea L.) para acabamento de cordeiros. Ciencia Rural, v.34, n.2, p.499-504, 2004.

BURNS, J.C.; POND, K.R.; FISHER, D.S. Measurament of forage intake. In: FAHEY JR., G.C. (Ed.) Forage quality, evaluation and utilization. Madison: America Society of Agronomy, 1994. p.494-531.

EMPRESA BRASILEIRA DE PESQUISA AGROPECUÁRIA EMBRAPA. Sistema brasileiro de classificação de solos. Brasília, 1999. 412p.

EMPRESA BRASILEIRA DE PESQUISA E AGROPECUÁRIA EMBRAPA - Centro Nacional de Pesquisa Tecnológica em Informática para a Agricultura. SWNTIA. Versão 4.2.1. Instalação e programa. Campinas, 1996. v.3, Disquete.

FERREIRA, M.A. Utilização da palma forrageira na alimentação de vacas leiteiras. In: SIMPÓSIO NORDESTINO DE ALIMENTAÇÃO DE RUMINANTES, 9., 2005, Campina Grande. Anais... Campina Grande: SNPA/UFPB, 2005. (CD-ROM).

FIGUEIREDO, D.M.; PAULINO, M.F.; DETMANN, E. et al. Fontes de proteína em suplementos múltiplos para bovinos em pastejo no período das águas. Revista Brasileira de Zootecnia, v.37, n.12, p.2222-2232, 2008.

HERD, D.B. Mineral supplementation of beef cows in Texas. 1997. Disponível em: <http://zeta.hpnc.com/ sharonw/ Ranching>. Acesso em: 2/10/2005.

HORN, G.W.; McCOLLUN, F.T. Energy supplementation of grazing ruminants. In: GRAZING LIVESTOCK NUTRITION CONFERENCE, 1987, Jackson. Proceedings... Jackson: [s.n.], 1987. p.125-136.

ÍTAVO, L.C.V.; VALADARES FILHO, S.C.; SILVA, F.F. et al. Comparação de indicadores e metodologias de coleta para estimativas de produção fecal e fluxo de digesta em bovinos. Revista Brasileira de Zootecnia, v.31, n.4, p.1833-1839, 2002.

LIMA, J.B.M.P.; GRAÇA, D.S.; BORGES, A.L.C.C. et al. Uso do óxido crômico e do $\operatorname{LIPE}^{\circledR}$ na estimativa do consumo de matéria 
seca por bezerros de corte. Arquivo Brasileiro de Medicina Veterinaria e Zootecnia, v.60, n.5, p.1197-1204, 2008.

LIRA, M.A.; SANTOS, M.V.F.; CUNHA, M.V. et al. A palma forrageira na pecuária do semi-árido. In: GOMIDE, C.A.M..; RANGEL, J.H.A.; MUNIZ, E.N. et al. (Orgs.). Alternativas alimantares para ruminantes. Aracaju: Embrapa Tabuleiros Costeiros, 2006. p.17-34.

LOPES, H.O.S.; PEREIRA, E.A.; NUNES, I.J. et al. Suplementação de baixo custo para bovinos: mineral e alimentar. Brasília: EMBRAPA-SPI, 1998. 107p.

MARQUES, A.V.M.S.; COSTA, R.G.; SILVA, A.M.A. et al. Feno de flor de seda (Calotropis procera SW) em dietas de cordeiros Santa Inês: Biometria e rendimento dos componentes nãoconstituintes da carcaça. Revista Brasileira de Ciências Agrárias, v.3, n.1, p.85-89, 2008.

MOREIRA, J.N.; LIRA, M.A.; SANTOS, M.V.F. et al. Caracterização da vegetação de Caatinga e da dieta de novilhos no Sertão de Pernambuco. Pesquisa Agropecuária Brasileira, v.41, n.11, p.1643-1651, 2006.

MOREIRA, J.N.; LIRA, M.A.; SANTOS, M.V.F. et al. Consumo e desempenho de vacas guzerá e girolando na caatinga do sertão pernambucano. Caatinga, v.20, n.3, p.13-21, 2007.

MOURA, J.W.S. Disponibilidade e qualidade de pastos nativos e de capim Buffel (Cenchrus ciliaris, L.) diferido no semiárido de Pernambuco. 1987. 159f. Dissertação (Mestrado em Produção Animal) - Universidade Federal Rural de Pernambuco, Recife.

NATIONAL RESEARCH COUNCIL - NRC. Nutrient requirements of dairy cattle. 7.ed. Washington, D.C.: 2001. 381p.

PAULINO, M.F. Suplementação energética e protéica de bovinos de corte em pastejo. In: SIMPÓSIO GOIANO SOBRE MANEJO E NUTRIÇÃO DE BOVINOS, 3., 2001, Goiânia. Anais... Goiânia: CBNA, 2001. p.121-154.

PAULINO, M.F.; ZERVOUDAKIS, J.T.; MORAES, E.H.B.K. et al. Bovinocultura de ciclo curto em pastagens. In: SIMPÓSIO DE PRODUÇÃO DE GADO DE CORTE, 3., 2002, Viçosa, MG. Anais... Viçosa, MG: UFV, 2002. p.153-196.

ROMNEY, D.L.; GILL, M. Intake of forages. In: GIVENS, D.I.; OWENS, E.; AXFORD, R.F.E. (Ed.) Forage evaluation in ruminant nutrition. Wallingford: CABI, 2000. p.43-62.

ROONEY, L.W. Ten myths about tannins in sorghums. Journal of SAT Agricultural Research, v.1, n.1, p.1-3, 2005.
RUAS, J.R.; TORRES, C.A.A.; VALADARES FILHO, S.C. et al. Efeito da suplementação protéica a pasto sobre consumo de forragens, ganho de peso e condição corporal, em vacas Nelore. Revista Brasileira de Zootecnia, v.29, n.3, p.930-934, 2000.

SANTOS, G.R.A.; BATISTA, A.M.V.; GUIM, A. et al. Composição química e degradabilidade in situ da ração em ovinos em área de caatinga no sertão de Pernambuco. Revista Brasileira de Zootecnia, v.38, p.384-391, 2009.

SILVA, D.J.; QUEIROZ, A.C. Análise de alimentos: métodos químicos e biológicos. Viçosa, MG: UFV, 2002. 235p.

SILVA, V.M.; ARAÚJO FILHO, J.A.; REGO, M.C. et al. Desempenho de bovinos e da pastagem em diferentes níveis de manipulação da Caatinga. Pesquisa Agropecuária Pernambucana, v.12, n. especial, p.99-107, 2000-2001.

SNIFFEN, C.J.; O'CONNOR, J.D.; VAN SOEST, P.J. A net carbohydrate and protein system for evaluating cattle diets. II. Carbohydrate and protein availability. Journal of Animal Science, v.70, p.3562-3577, 1992.

THIAGO, L.R.L.S.; COSTA, F.P. Terminação de bovinos na entressafra. Campo Grande: Embrapa Gado de Corte, 2004. 10p. (Comunicado Técnico, 22).

WILLIAMS, C.H.; DAVID, D.J.; ILSMA, A.O. The determination chromic oxide in faeces samples by atomic absorption spectrophotometry. Journal of Agricultural Science, v.59, p.381-385, 1962

VALADARES FILHO, S.C.; ROCHA JR., V.R.; CAPPELLE, E.R. Tabelas brasileiras de composição de alimentos para bovinos. Viçosa, MG: UFV, 2002. 297p.

VAN SOEST, P.J.; ROBERTSON, J.B.; LEWIS, B.A. Methos for extraction fiber, neutral detergent fiber and nonstarch polysaccarides in relation to animal nutrition cows. Journal of Dairy Science, v.83, n.1, p.3583-3597, 1991.

YDOYAGA SANTANA, D.F. Caracterização da caatinga, consumo e desempenho de novilhas das raças guzerá e girolando, suplementadas durante o período chuvosos, em Serra Talhada-PE. 2006. 60f. Tese (Doutorado em Zootecnia) - Universidade Federal Rural de Pernambuco, Recife.

YDOYAGA SANTANA, D.F.; LIRA, M.A.; SANTOS, M.V.F. et al Caracterização da dieta de novilhos fistulados na caatinga, na época chuvosa, em Serra Talhada - PE. Archivos Latinoamericanos de Reproducción Animal, v.13, supl. 1, p.194, 2005. 